\title{
Drying Condition and Qualities of Rapeseed and Sunflower
}

\author{
Genta KANAI*, Hitoshi KATO, Naonobu UMEDA ${ }^{1}$, Kensuke OKADA ${ }^{2}$ and \\ Morio MATSUZAKI
}

Biomass Production and Processing Research Team, National Agriculture Research Center, National Agriculture and Food Research Organization (Tsukuba, Ibaraki 305-8666, Japan)

\begin{abstract}
We examined drying condition and its effects on qualities of rapeseed and sunflower, especially on oil qualities as measured by POV (peroxide value), AV (acid value) and color of oil. Initial moisture contents for rapeseed (Norin-48, Kirariboshi) were 38.7\% w.b., 31.1\% and 15.1\% and for sunflower (Pioneer 63 M80, Harurinzo) $31.5 \%$ w.b. and $15.8 \%$. Each sample was dried unheated in a ventilation dryer for $24 \mathrm{hr}$, dried in an oven at $45^{\circ} \mathrm{C}, 55^{\circ} \mathrm{C}$ or $65^{\circ} \mathrm{C}$ for $24 \mathrm{hr}$, or dried in a circulating dryer (capacity: 1t) at unheated $-55^{\circ} \mathrm{C}$ for $11 \mathrm{hr}$. Samples were expressed for oil with a small expeller. The oil samples were examined for POV, AV and the color of oil. POV of rapeseed oil was from $0.8 \mathrm{meq} / \mathrm{kg}$ for $45^{\circ} \mathrm{C}$ drying with $15.1 \%$ initial moisture content to $10.8 \mathrm{meq} / \mathrm{kg}$ for $65^{\circ} \mathrm{C}$ with $38.7 \%$ initial moisture content. POV of sunflower oil was from $1.9 \mathrm{meq} / \mathrm{kg}$ for $45^{\circ} \mathrm{C}$ drying with $15.8 \%$ initial moisture content to $6.8 \mathrm{meq} / \mathrm{kg}$ for $65^{\circ} \mathrm{C}$ with $31.5 \%$ initial moisture content. The early harvested rapeseed dried under higher temperature conditions had not only low oil quality measured by POV but also a green color stemming from chlorophyll. For AV a tendency that grain with higher moisture contents had higher AV was implied. According to the results, to avoid the degradation of oil quality the grain should be mature and initial moisture contents low enough to prevent deterioration; if the harvested rapeseed or sunflower grain have high moisture content, drying at lower temperatures is better to maintain the qualities of oil.
\end{abstract}

Discipline: Postharvest technology

Additional key words: acid value, peroxide value

\section{Introduction}

Recently the area of oil crops has increased rapidly because of a growing expectation of demand for bio-fuels made from vegetable oil. Among the oil crops oil palm has a very high yield of oil producing $3,800 \mathrm{~kg} / \mathrm{ha}$, compared to rapeseed with $1,000 \mathrm{~kg} / \mathrm{ha}$ and sunflower with $740 \mathrm{~kg} / \mathrm{ha}$. However, a two crop system of rapeseed and sunflower has the potential of producing half the yield of oil palm in Japan ${ }^{7}$. Unfortunately in some areas farmers do not have enough experience in growing, harvesting and drying rapeseed and sunflower. In Japan because of its very humid climate the drying process is inevitable for most crops but there is not enough knowledge about how to dry rapeseed and sunflower. Sometimes it is difficult to harvest the crop at an appropriately dried condition because of the weather. There have been some studies on qualities of oils and drying condition of oilseeds ${ }^{8,9}$, but research on oilseeds harvested with high moisture content ${ }^{6}$ is not a major topic because harvesting occurs at a sufficiently dried condition in most oilseed areas.

Here the drying condition and its effects on the qualities of rapeseed and sunflower, especially on oil qualities, were examined to clarify the appropriate conditions for rapeseed and sunflower in a machine drying. In addition, to deal with the Japanese weather conditions high moisture content grains were examined.

\section{Materials and methods}

\section{Materials and initial moisture contents}

Rapeseed (Norin-48, Kirariboshi) was grown with the usual cultivation methods from October 2005 to June 2006 in a field at Tsukuba City, Ibaraki Prefecture, Japan. Samples were collected three times, designated I, II and III

\footnotetext{
Present address:

${ }^{1}$ Bio-oriented Technology Research Advancement Institution (Saitama, Saitama 331-8537, Japan)

${ }^{2}$ Japan International Research Center for Agricultural Sciences (Tsukuba, Ibaraki 305-8686, Japan)

*Corresponding author: e-mail kanaigen@affrc.go.jp

Received 30 November 2008; accepted 22 June 2009.
} 
Table 1. Sample conditions

\begin{tabular}{|c|c|c|c|c|c|c|c|}
\hline & & $\begin{array}{l}\text { Moisture content } \\
\text { (w.b.\%)* }\end{array}$ & $\begin{array}{l}\text { Days after } \\
\text { seeding }\end{array}$ & $\begin{array}{c}\text { 1,000 kernel } \\
\text { weight (g) D.M. }\end{array}$ & $\begin{array}{c}\text { Total fat content } \\
\text { (\% D.M.) }\end{array}$ & $\begin{array}{l}\text { Seeding } \\
\text { date }\end{array}$ & $\begin{array}{c}\text { Harvesting } \\
\text { date }\end{array}$ \\
\hline \multirow{3}{*}{ Rapeseed } & I & 38.7 & 245 & $3.01 \mathrm{a}$ & $49.2 \mathrm{e}$ & 12 -Oct-05 & 14-Jun-06 \\
\hline & II & 31.1 & 246 & $3.04 \mathrm{~b}$ & $50.5 \mathrm{e}$ & 12-Oct-05 & 15-Jun-06 \\
\hline & III & 15.1 & 252 & $3.00 \mathrm{a}$ & $49.0 \mathrm{e}$ & 12-Oct-05 & 21-Jun-06 \\
\hline \multirow{2}{*}{ Sunflower } & IV & 31.5 & 100 & $49.9 \mathrm{c}$ & $47.6 \mathrm{f}$ & 10-Jul-06 & 18-Oct-06 \\
\hline & $\mathrm{V}$ & 15.8 & 113 & $65.9 \mathrm{~d}$ & $48.1 \mathrm{f}$ & 20-Jun-06 & $11-$ Oct-06 \\
\hline
\end{tabular}

*: Values in a column followed by the same letter do not differ from each other at the $5 \%$ level of significance.

as shown in Table 1.

Sunflower (Pioneer 63M80, Harurinzo) was grown with the usual cultivation methods from June to October of 2006 also in a field at Tsukuba City. Samples were collected two times designated IV and V as shown in Table 1.

All samples were harvested with a combine from a field of more than 10 a. Samples were collected from well mixed bulk grain discharged from the combine. Moisture contents were measured with $10 \mathrm{~g}$ (grain) using a $105^{\circ} \mathrm{C}$ 24 hour method ${ }^{5}$ for three times or repetitions. The 1,000 kernel weight was measured 5 times for each sample and expressed as dry matter weight. Total fat contents were measured with the Büchi B-820, Caviezel method, for 3 times or repetitions for each sample and expressed as percent value of dry matter weight.

\section{Drying settings}

Samples were dried with unheated or heated air as follows; A: unheated, B: $45^{\circ} \mathrm{C}, \mathrm{C}: 55^{\circ} \mathrm{C}$, and D: $65^{\circ} \mathrm{C}$ to fix the best drying temperature for each moisture content. In addition, E: a circulating dryer was also examined for II and IV. The dryer is very popular in Japanese rice farming and it is expected to be utilized for drying rapeseed and sunflower.

Drying settings are shown in Table 2. For "A" a ventilation dryer (Issingo Kaneko Agricultural Machinery Co., Ltd.) was used with the burner off. The dryer has a $6.6 \mathrm{~m}^{2}$ mesh deck and air flows upward from a blower $(0.75 \mathrm{~kW})$ through the mesh. For "B" to "D" a drying oven (Espec Convection Oven LC-123) was used. For "E" a circulating dryer was used (Iseki GA100, capacity: 400-1,200 $\mathrm{kg}$ for wheat). Normally the drying temperature of air is regulated by the on/off of the burner based on the moisture content and quantity of the grain. However, the dryer was not adapted for use with rapeseed or sunflower grain and we stopped the electric sensor for grain moisture of the dryer. The drying temperature was observed between the unheated condition, the same as the ambient temperature, and $55^{\circ} \mathrm{C}$.
Table 2. Drying settings

\begin{tabular}{cccc}
\hline \hline & Dryer & $\begin{array}{c}\text { Air temperature } \\
\left({ }^{\circ} \mathrm{C}\right)\end{array}$ & $\begin{array}{c}\text { Duration time } \\
\text { of drying } \\
\text { (hour) }\end{array}$ \\
\hline A & Ventilation dryer & Unheated & 24 \\
\hline B & Drying oven & 45 & 24 \\
\hline C & Drying oven & 55 & 24 \\
\hline D & Drying oven & 65 & 24 \\
\hline E & Circulating dryer & Unheated -55 & 11 \\
\hline
\end{tabular}

Each sample of "A" to "D" was almost $2 \mathrm{~kg}$ and packed in $30 \mathrm{~cm} \times 40 \mathrm{~cm}$ plastic mesh bags. The sample of "E" was dried as bulk grain. For each setting one sample was prepared. After drying each sample, samples were preserved under conditions of $10^{\circ} \mathrm{C}$ in a refrigerator.

\section{Expression of oil sample}

A small expeller (San-Seiki S100-200, capacity: 3.5 $\mathrm{kg} / \mathrm{h}$ ) was used for expression (cold press) of samples. Moisture contents of samples were 5-6\% when expelled. Yield of oil was $20-30 \%$ of the input grain weight.

\section{Evaluation of oil qualities}

Expelled oil samples were examined for POV (peroxide value), AV (acid value) and the color of oil. POV and AV are used as indices for degradation of oil and referred to as food constituents. POV increases when the oil is oxidized, and AV increases when oil is hydrolyzed. The AV is also known as being proportional to free fatty acid (FFA). The measurement of POV and AV were held at Japan Institute of Oil, Fats \& Other Foods Inspection Foundation based on Standard Methods for the Analysis of Fats, Oils and Related Materials (Japan Oil Chemists' Society) for one sample for each.

Color of oil was judged by the naked eye. In addition, for rapeseed oil the colors of the samples were 
measured with a spectrophotometer (UV2550, Shimazu). The results of the spectrophotometer observation were expressed as chlorophyll density using the following conversion formula based on Standard Methods for the Analysis of Fats, Oils and Related Materials (Japan Oil Chemists' Society).

$$
\begin{aligned}
& \text { Chlorophyll density }(\mathrm{ppm})= \\
& \left.\qquad A_{670}-1 / 2\left(A_{630}+A_{710}\right)\right\} / 0.0964 L \\
& A_{X}: \text { Absorbance of the wave length } X \mathrm{~nm} \\
& L: \text { Width of the liquid in the cell }
\end{aligned}
$$

\section{Results and discussion}

\section{Sample condition}

Sample conditions are shown in Table 1. For rapeseed the sample harvesting times were 245 (I), 246 (II) and 252 (III) days after seeding and moisture contents were 38.7 (I), 31.1 (II) and 15.1\% (III). The 1,000 kernel weights were $3.01 \mathrm{~g}$ (I), $3.04 \mathrm{~g}$ (II) and $3.00 \mathrm{~g}$ D.M. (III). The kernel weights of "I and II" and "II and III" were significantly different at the $5 \%$ probability level. The kernel weight difference seemed to stem from the difference in locations of the field.

For sunflower, sample IV was harvested 100 days after seeding and had kernel weight of $49.9 \mathrm{~g}$; V harvested 113 days after seeding had kernel weight of $65.9 \mathrm{~g}$. The kernel weight of IV and V was significantly different at the $5 \%$ level of probability. The kernel weight difference seemed to stem from the difference in locations of the field and the difference in seeding date. IV and V had been grown in the same field but seeded at different dates.

\section{Peroxide Value (POV)}

Figure 1 shows POV of rapeseed dried under each setting. When the initial moisture content was $38.7 \%$ (I),

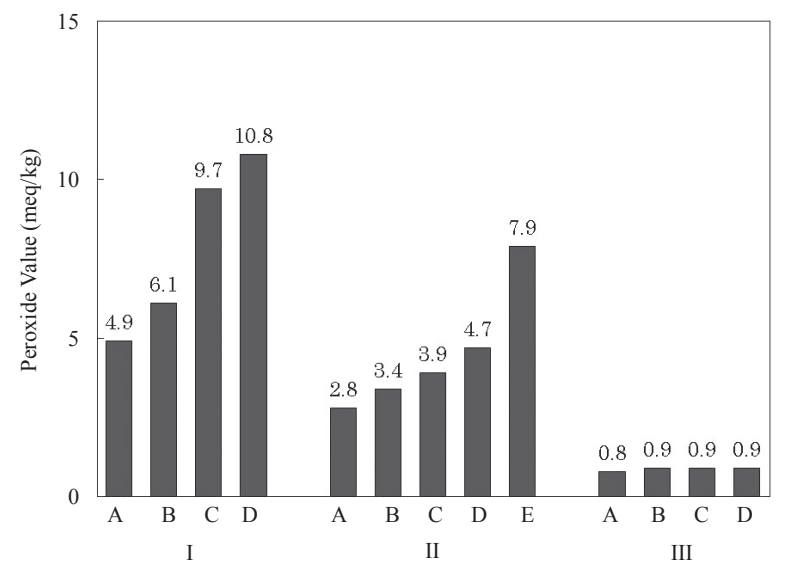

Fig. 1. Drying conditions and POV of rapeseed oil the " $\mathrm{D}$ " setting had the highest POV followed by "C", " $\mathrm{B}$ " and the lowest was " $\mathrm{A}$ ". When the initial moisture content was $31.1 \%$ (II), the "E" setting had the highest POV followed by "D", "C", "B", and the lowest was "A". Furthermore, when the initial moisture content was $15.1 \%$ (III), "A" had a value of 0.8 and "B", "C" and "D" had values of 0.9 .

The results showed that a higher drying temperature was associated with a higher POV, especially in the higher initial moisture contents of $38.7 \%$ (I) and $31.1 \%$ (II). The tendency was not clear in the low initial moisture content of $15.1 \%$ (III). However, because the samples had no repetition it is difficult to discuss the results based on the statistical analysis for the tendency.

The results also showed the effect of the initial moisture content on POV. When the initial moisture content was higher, the POV was also higher. Comparisons of POV for drying condition are as follows, in drying condition "A": I $(\mathrm{POV}=4.9)>$ II (2.8) > III (0.8), in "B": I (6.1) > II (3.4) > III (0.9), in "C": I (9.7) > II (3.9) > III (0.9), and in "D": I (10.8) > II (4.7) > III (0.9). The samples had no repetition and this makes it difficult to discuss the results based on statistical analysis for the tendency. However, the tendency was analyzed statistically by treating the POV of "A"- $D$ " as the repetitions for each harvesting date, I-III. Based on Welch's t-test, POV of III was significantly lower than that of I and II, at the 5\% and $1 \%$ probability levels, respectively.

Figure 2 shows POV of sunflower dried under each setting. When the initial moisture content was $31.5 \%$ (IV), the "E" setting had the highest POV followed by " $D$ ", "C", "B", and the lowest was "A". When the initial moisture content was $15.8 \%(\mathrm{~V})$, " $\mathrm{D}$ " setting had the highest POV followed by "C", "B" and the lowest was "A".

The results showed that the higher drying temperatures had higher POV. The tendency was stronger in the

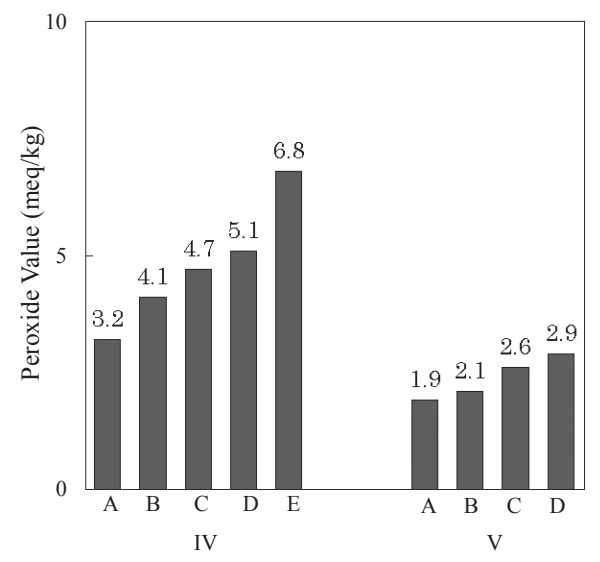

Fig. 2. Drying conditions and POV of sunflower oil 
higher initial moisture content of IV (31.5\%) than in V $(15.8 \%)$. However, because of no repetition of the samples it is difficult to discuss the results based on statistical analysis for the tendency.

Generally oil oxidation is known to be accelerated by increased temperature ${ }^{10}$. Our study was on oilseeds not on the oil, but the tendency of the results, higher drying temperatures had higher POV, did not contradict that. For the drying of moisture conditioned grains the POV was reported to be proportional to the drying temperature from $25^{\circ} \mathrm{C}$ to $90^{\circ} \mathrm{C}^{1}$, showing the same tendency.

The results also showed the effect of the initial moisture content on POV. POV of IV (31.5\%) was higher than $\mathrm{V}(15.8 \%)$ in all drying conditions from " $\mathrm{A}$ " to "D." No repetition of the samples makes it difficult to discuss the results based on statistical analysis for the tendency. However, here the tendency is discussed statistically by treating the POV of "A"- D" as the repetitions for each harvesting date, IV and V. Based on Welch's t-test, POV of V was significantly lower than that of IV at the $5 \%$ level of probability.

The POV should be under 10 (milliequivalents of active oxygen $/ \mathrm{kg}$ oil) for edible oil obtained by cold press according to the Codex Stan $210^{2}$. The POV of both rapeseed and sunflower oil had values fulfilling the standard.

\section{Acid Value (AV)}

Figure 3 shows AV of rapeseed dried under each setting. The AV of rapeseed did not show any effects of the drying condition. However, there is a report that shows higher drying temperatures had higher FFA for rapeseed with initial moisture content adjusted to $20 \%{ }^{8}$. In the report the moisture content of grain was conditioned to $20 \%$. In addition, the effect of field deterioration may be different every year and for every location. Those differences may be the reason that our results did not show the same tendency as the report.

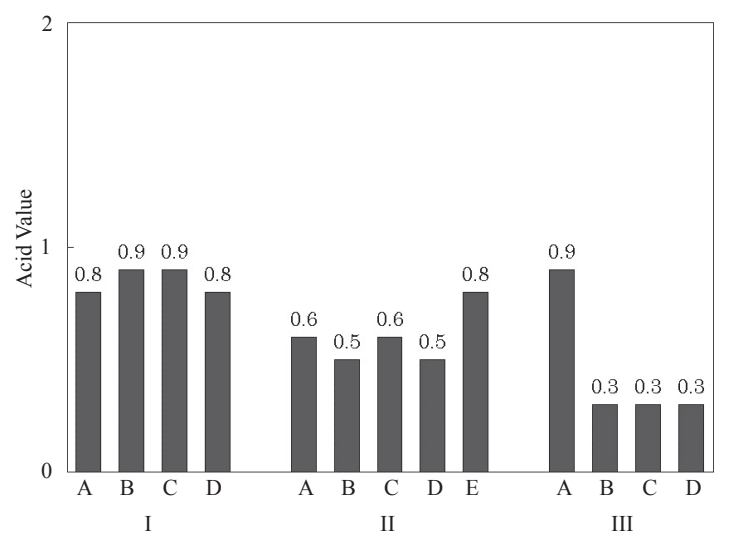

Fig. 3. Drying conditions and AV of rapeseed oil
An effect of the initial moisture content on AV was implied. Comparisons of AV for drying condition are as follows, in drying condition "A": I $(\mathrm{AV}=0.8)>\mathrm{II}(0.6)$ < III (0.9), in "B": I (0.9) > II (0.5) > III (0.3), in "C": I $(0.9)>$ II $(0.6)>$ III $(0.3)$, and in "D": I (0.8) > II $(0.5)>$ III (0.3). The tendency that higher initial moisture contents had higher AV was observed except in III-A. III-A showed strangely high AV but the reason has not been identified. No repetition of the samples makes it difficult to discuss the results based on statistical analysis for the tendency. However, here the tendency is discussed statistically by treating the AV of "A"-"D" as the repetitions for each harvesting date, I-III. AV of II was significantly lower than that of I based on Welch's t-test at the 5\% level of probability.

Figure 4 shows AV of sunflower dried under each setting. The AV of sunflower did not show any effects of the drying condition. For the drying of moisture conditioned grains the FFA was reported to be proportional to drying temperatures from $25^{\circ} \mathrm{C}$ to $90^{\circ} \mathrm{C}^{1}$. The examination of grain with $15 \%$ to $43 \%$ moisture contents and dried at temperatures of $35^{\circ} \mathrm{C}$ to $88^{\circ} \mathrm{C}$ is reported to show the FFA increasing with drying temperature without statistical validity ${ }^{6}$. However, here the results did not show this tendency. One reason for the difference from the first case can be explained by the difference in the sample preparation for drying. In the report the moisture content of grain was conditioned to $28 \%$ by spraying grain with distilled water. In addition, the effect of field deterioration may be different every year and for every location.

The tendency that higher initial moisture contents had higher AV was observed in drying conditions " $A$ ""D", IV (0.4) > V (0.3). No repetition of the samples makes it difficult to discuss the results based on statistical analysis for the tendency. However, here the tendency is discussed with statistical analysis by treating the AV of "A"-"D" as the repetitions for each harvesting date, IV and

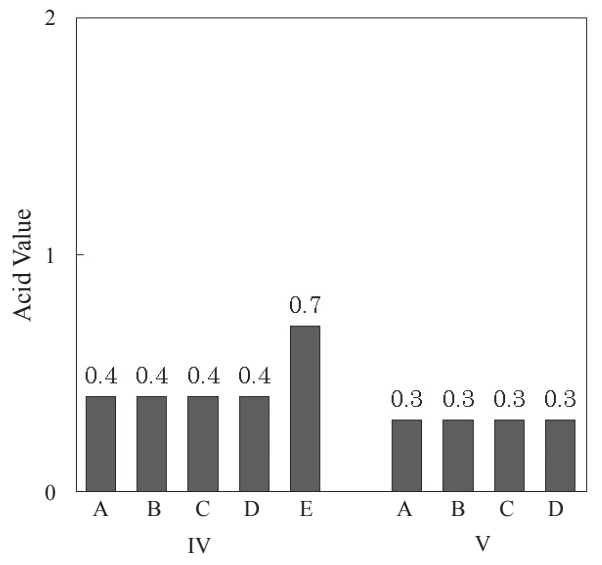

Fig. 4. Drying conditions and AV of sunflower oil 
V. AV of IV was significantly higher than that of $\mathrm{V}$ based on Welch's t-test at the $1 \%$ level of probability but there is a report ${ }^{6}$ which found the opposite tendency of the FFA to initial moisture content. In the report the samples with $15 \%$ initial moisture content had significantly higher AV than that of samples with $22 \%$ to $43 \%$ moisture contents for drying temperatures of $35^{\circ} \mathrm{C}$ to $88^{\circ} \mathrm{C}$. In this case differences in field deterioration may have occurred between harvesting of the $15 \%$ grain sample and $22 \%$ grain sample.

The AV should be under 4.0 (mg KOH/g fat or oil) for edible oil obtained by cold press according to the $\mathrm{Co}$ $\operatorname{dex} \operatorname{Stan} 210^{2}$. The AV of both rapeseed and sunflower oil had values fulfilling the standard. The drying conditions did not seem to have enough effect on deterioration of grain to influence AV. It is implied that grain with higher initial moisture contents had higher AV.

\section{Color of oil}

According to the observations by the naked eye, the rapeseed oil color of "A", "B", "C", and "D" of I, and "C", "D" and "E" of II was slightly green. The intensity of green seemed to be proportional to the POV. However, those of "A" and "B" of II, and all of III had almost the same color of light yellow. The results seemed to indicate a relationship with the ratio of immature green rapeseed grain in each sample.

Figure 5 shows the chlorophyll density of rapeseed oil samples according to the results of the spectrophotometer observation. The intensity of green observed by the naked eye seemed to be almost proportional to the chlorophyll density. Chlorophyll is a green coloring matter and seemed to have an effect on the oil color. There was a report that grain with higher green seed ratio had higher chlorophyll density of seeds and that higher chlorophyll

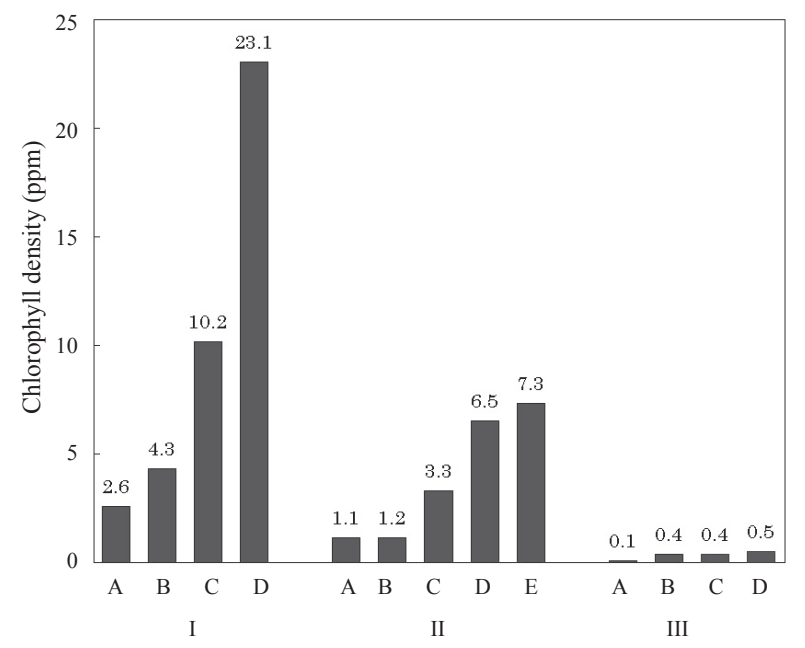

Fig. 5. Drying conditions and chlorophyll density of rapeseed density of seeds had higher chlorophyll density of oil ${ }^{3}$.

Chlorophyll density of rapeseed oil was higher when the drying temperature was higher. The reason for the tendency could be explained by chlorophyllase activity. Chlorophyll is decomposed by chlorophyllase. In addition, chlorophyllase generally shows maximum activity at $30^{\circ} \mathrm{C}$ to $40^{\circ} \mathrm{C}^{4}$. That implies the tendency of the results can be explained by drying condition $\mathrm{D}$ having the highest temperature outside this range, the lowest activity of chlorophyllase and the highest density of chlorophyll, followed by $\mathrm{C}, \mathrm{B}$ and A. Furthermore, chlorophyll and its derivatives in the oil have been reported to accelerate oxidation ${ }^{11}$ that seemed to be related with the chlorophyll contents and were almost proportional to POV.

Based on the observations by the naked eye, the sunflower oil color of all of IV and V was almost the same color of light yellow. Chlorophyll density was not measured for sunflower oil.

\section{Conclusions}

We examined the drying condition and its effects on oil qualities of rapeseed and sunflower as measured by POV (peroxide value), AV (acid value) and color of oil. The examination includes grains with high moisture contents to deal with harvesting in rainy weather condition. The conclusions of this study are as follows.

1) $\mathrm{POV}$ of rapeseed oil was from $0.8 \mathrm{meq} / \mathrm{kg}$ for $45^{\circ} \mathrm{C}$ drying with $15.1 \%$ initial moisture content to $10.8 \mathrm{meq} / \mathrm{kg}$ for $65^{\circ} \mathrm{C}$ with $38.7 \%$ initial moisture content. POV, green color intensity and chlorophyll density seemed to increase when drying temperature increased. In addition, they also increased when initial moisture content increased.

2) $\mathrm{POV}$ of sunflower oil was from $1.9 \mathrm{meq} / \mathrm{kg}$ for $45^{\circ} \mathrm{C}$ drying with $15.8 \%$ initial moisture content to $6.8 \mathrm{meq} /$ $\mathrm{kg}$ for $65^{\circ} \mathrm{C}$ with $31.5 \%$ initial moisture content. POV seemed to increase when drying temperature increased. Furthermore, POV also increased when initial moisture content increased. No tendency was observed here for the color of sunflower oil in any drying condition.

3) The drying conditions did not seem to have enough effect on deterioration of both rapeseed and sunflower to influence AV. It is implied that grain with higher initial moisture contents had higher AV.

4) According to the results for avoiding the degradation of oil quality, to keep POV and AV low, the initial moisture content should be low enough to prevent quality deterioration; if the harvested rapeseed or sunflower grain have high moisture contents, drying at lower temperatures is better for maintaining the qualities of oil. 


\section{References}

1. Bax, M. M., Gely, M. C. \& Santalla, E. M. (2004) Prediction of crude sunflower oil deterioration after seed drying and storage processes. J.Am.Oil Chem. Soc., 81(5), 511-515.

2. Codex Alimentarius Commission (1999) Codex standard for named vegetable oils. Codex Stan 210 (Amended 2003, 2005). http://www.codexalimentarius.net/download/standards/336/CXS_210e.pdf.

3. Daun, J. K. (1982) The relationship between rapeseed chlorophyll, rapeseed oil chlorophyll and percentage green seeds. J.Am.Oil Chem. Soc., 59(1), 15-18.

4. Drazkiewicz, M. (1994) Chlorophyllase: occurrence, functions, mechanism of action, effects of external and internal factors. Photosynthetica, 30(3), 321-331.

5. Japanese Society of Agricultural Machinery (1977) Nogyo kikai shisetsu shikenhoho binran (Methods of experiments for agricultural machinery and agricultural structures). Japanese Society of Agricultural Machinery, Tokyo, 199-200 [In Japanese].

6. Morrison III, W. H. \& Robertson, J. A. (1978) Effects of drying on sunflower seed oil quality and germination. J.Am.Oil Chem. Soc., 55, 272-274.

7. Okada, K., Matsuzaki, M. \& Yasumoto, S. (2007) Oil crops researches for biofuel purposes in Japan. Nogyo gijutsu (Journal of Agricultural Science), 62(3), 130-135 [In Japanese].

8. Pathak, P. K., Agrawal, Y. C. \& Singh, B. P. N. (1991) Effect of elevated drying temperature on rapeseed oil quality. J.Am.Oil Chem. Soc., 68(8), 580-582.

9. Sutherland, J. W. \& Ghaly, T. F. (1982) Heated-air drying of oilseeds. J. Stored Prod. Res., 18, 43-54.

10. Tautorus, C. L. \& McCurdy, A. R. (1990) Effect of randomization on oxidative stability of vegetable oils at two different temperatures. J.Am.Oil Chem. Soc., 67(8), 525530.

11. Tautorus, C. L. \& Low, N. H. (1994) Possible causes for decreased stability of canola oil processed from green seed. J.Am.Oil Chem. Soc., 71(10), 1123-1128.

12. Todorov, D. T. et al. (2003) Chlorphyllase activity and chlorophyll content in wild type and eti5 mutant of Arabidopsis thaliana subjected to low and high temperatures. Biologia plantarum, 46(4), 633-636. 